\title{
Formação gerencial: uma análise da oferta dos programas de pós-graduação lato sensu de Gestão Empresarial do Rio Grande do Sul
}

\author{
Management education: an analysis of the supply of broad post-graduation programs of \\ management of Rio Grande do Sul
}

Tamara Cecilia Karawejczyk ${ }^{1}$

Centro Universitário La Salle-Unilasalle / Programa de pós-graduação em memória social e bens culturais, Canoas - RS, Brasil

\begin{abstract}
Resumo
O objetivo deste estudo é discutir o oferecimento de produtos e serviços, no âmbito dos programas em nível de pósgraduação lato sensu, pelas instituições de ensino superior do Rio Grande do Sul. Este artigo é um recorte de um projeto de pesquisa (2011-2013), que tinha por objetivo identificar e analisar as contribuições para o desenvolvimento de competências dos gestores na participação em programas de educação gerencial em nível de pós-graduação lato sensu, mais especificamente os chamados de Master in Business Administration (MBA). Os investimentos em formação gerencial crescem ano após ano (RAELIN, 2006; 2011), porém, pode-se dizer que tanto a literatura acadêmica quanto a pesquisa ainda carecem de maior entendimento sobre a efetividade dos programas gerenciais oferecidos no mercado educacional (BOLT, 1993; LORANGE, 1994; RUAS, 2003; ANTONELLO e RUAS, 2005). Este estudo é classificado como qualitativo e exploratório, sendo que a coleta de dados ocorreu através de dados secundários, documentos institucionais, sites das IES e entrevistas semiestruturadas, com coordenadores dos programas e também com especialistas em formação gerencial. Para a análise dos dados, foram utilizadas referências da análise historiográfica e da construção de mapas, pois as mesmas apresentam modos de reconfigurar o corpus documental. Os resultados são discutidos à luz de autores e pesquisas sobre formação gerencial, apontando que, se por um lado, há uma crescente preocupação com investimentos neste tipo de formação, seja por parte das empresas ou por parte dos gestores que buscam esses programas, por outro, ainda existe um longo caminho que as IES necessitam trilhar para uma contribuição efetiva nesse tipo de formação.
\end{abstract}

Palavras-chave: Formação gerencial. Programas de pós-graduação lato sensu. MBA em Gestão Empresarial.

\begin{abstract}
The aim of this study is to discuss the products and services offered in the graduate specialization programs by institutions of higher education in Rio Grande do Sul, Brazil. This article is an excerpt of a research project (2011-2013) that aimed to identify and analyze the contributions to the development of skills of managers when participating in Graduate Specialization Programs on Management Training, more specifically the so-called Master of Business Administration (MBA) in business management. Investments in management education grow year after year (Raelin, 2006; 2011), but we can say that both academic literature and research still lack a greater understanding of the effectiveness of management programs offered in the educational market (BOLT, 1993; LORANGE, 1994; RUAS, 2003; ANTONELLO and RUAS, 2005). This study is classified as qualitative and exploratory, and data were collected through secondary data, institutional documents and higher education institutions websites, as well as semi-structured interviews with coordinators of specialization programs and with experts on management training. To analyze data, references of
\end{abstract}

Artigo submetido em 11 de março de 2014 e aceito para publicação em 15 de dezembro de 2014.

DOI: http://dx.doi.org/10.1590/1679-395117900

${ }^{1}$ Doutora em administração pela escola de administração da UFRGS; Professora adjunta do Programa de pós-graduação em memória social e bens culturais do Unilasalle. Endereço: Unilasalle - Av. Victor Barreto, 2288, Centro, CEP 92010-000, Canoas-RS, Brasil. Email: tamara.karawejczyk@unilasalle.edu.br 
the historiographical analysis and the construction of maps, as they have ways to reconfigure the documentary corpusand content analysis were used. The results are discussed in light of authors and researches about management training, pointing out that, if on the one hand, there is a growing concern with investments in this sort of training, either by companies or by managers who seek these programs, on the other hand there is still a long way to be paved by higher education institutions for an effective contribution in this type of training.

Keywords: Management training. Graduate Specialization Programs. MBA in Business Management.

\section{Introdução}

Este artigo foi elaborado a partir do projeto de pesquisa "A construção de sentidos em processos de mudança: o desenvolvimento de aprendizagens coletivas e individuais em sujeitos que atuam em cargo de gestão”, financiado por uma instituição de ensino superior privada nos anos de 2011 a 2013. Tal projeto tinha por objetivo identificar e analisar as contribuições para o desenvolvimento de competências de gestores que participavam de programas de educação gerencial em nível de pós-graduação lato sensu, mais especificamente os chamados de Master in Business Administration (MBA) em gestão empresarial.

Esse projeto tinha duas etapas distintas, sendo (a) uma primeira, que consistiu na identificação e discussão sobre o oferecimento de produtos e serviços, no âmbito dos programas em nível de pós-graduação lato sensu, pelas instituições de ensino superior (IES) do Estado do Rio Grande do Sul (RS), através da percepção dos coordenadores desses programas e também de especialistas em formação gerencial; e (b) uma segunda etapa, para procurar compreender a apropriação do ensino oferecido por parte dos discentes frequentadores desses programas. Este artigo se configura mais especificamente como um subproduto da primeira parte desse projeto.

A complexidade da contemporaneidade se caracteriza por ser um período de grandes desafios para a sociedade humana. Desafios esses que se constroem pela superação das próprias dificuldades apresentadas em se lidar com a complexidade do mundo (MORIN, 1996; 2001). A emergência de novas realidades, tais como a globalização, a sociedade em rede, as cadeias, as tramas produtivas e a economia global, juntamente com discussões a respeito de governança e os avanços tecnológicos, impulsionam discussões sobre mudanças de paradigmas na educação e, por consequência, na formação gerencial, principalmente as relacionadas às atuais sustentações epistemológicas da teoria e prática gerencial.

Os investimentos em formação gerencial crescem ano após ano (RAELIN, 2006; 2011), porém pode-se dizer que, tanto a literatura acadêmica quanto a pesquisa, ainda carecem de um maior entendimento sobre a efetividade dos programas gerenciais oferecidos no mercado educacional (BOLT, 1993; LORANGE, 1994; RUAS, 2003; ANTONELLO e RUAS, 2005). As IES, sejam públicas ou privadas, disponibilizam um pacote de serviços e produtos relacionados a esse tema, principalmente na extensão universitária e na pós-graduação lato sensu e, em um fenômeno mais recente, nos mestrados profissionalizantes. Contudo, ainda existe certa incerteza com relação aos investimentos realizados: o que é transmitido em sala de aula é efetivamente aprendido e colocado em prática? Qual a sustentabilidade e o efeito das experiências em educação executiva realizadas? O que efetivamente traz mais retorno à educação formal ou à troca informal de experiências (ou um mix das duas formas)? O que deve ser preconizada: a formação ou a capacitação gerencial?

Formação gerencial, como categoria de análise, permite discussões iniciais relativas a duas categorias distintas: formação e capacitação. Maturana e Rezepka (2008) distinguem essas duas classes de fenômenos, esclarecendo que formação tem a ver com o desenvolvimento da pessoa e é um fundamento do processo educativo, enquanto a capacitação é a aquisição de habilidades e conhecimentos para a pessoa agir no mundo.

O avanço dos modelos de organização do trabalho e a transição de uma sociedade industrial para uma do conhecimento (POCHMANN, 2004) exigem não somente uma capacitação para a função gerencial como um 
recurso operacional, mas uma formação educativa, onde as pessoas possam ser cocriadoras com outros, de espaços de gestão e de trabalho. No mesmo sentido, Simões (2010) esclarece que as mudanças em curso influenciam o papel que a educação passa a ter na inserção das pessoas na vida profissional, tornando-se um elemento importante na trajetória de vida e de carreira.

Dessa forma, os vínculos entre formação e empregabilidade vão se formando. Frigotto esclarece: "os termos formação, educação, qualificação, requalificação, capacitação ganham complexidade e novos significados em consequência da nova realidade produtiva e organizacional do trabalho e dos diversos discursos e das ideologias geradas sobre a questão da formação no contexto das grandes transformações" (FRIGOTTO, 1998, p. 103).

As grandes transformações preconizadas por Frigotto (1998) são, muitas vezes, a mola propulsora para a aquisição de novas habilidades (capacitação) e conhecimentos no campo da educação gerencial, remetendo à discussão sobre qualificação e competência.

Compreende-se "qualificação" como "[...] um modelo que se consolidou a partir do taylorismo-fordismo, no qual se inscreveram padrões de formação, emprego, carreira e renda" (RAMOS, 2002, p. 401). Os avanços dos modelos de organização do trabalho exigiram um novo tipo de gestor, onde a noção de qualificação formal para o cargo acabou não sendo mais suficiente, pois os "empregados passaram a lidar com dilemas de gestão, precisando tomar decisões complexas, em tempo real, o que os obrigava a encontrar novas e difíceis soluções" (VIEIRA e LUZ, 2003, p.6). Nessa perspectiva, a noção de qualificação remete a um julgamento legitimado, que reconhece uma pessoa capaz de exercer uma profissão ou assumir um papel profissional (LE BOTERF, 2003).

Dessa forma, a concepção de qualificação formal ficava restrita ao cargo/função de cada trabalhador, sendo a ascensão profissional relacionada diretamente a um credenciamento escolar formal, ou seja, quanto mais o trabalhador estudava e obtinha os graus inerentes a esse estudo em instituições reconhecidas nacionalmente, mais ele ascendia na sua carreira profissional e ocupava posições na hierarquia da organização em que se encontrava.

Surge, então, a consolidação da noção de competência, que, segundo Le Boterf (2003), não pretende ser uma oposição à noção de qualificação, mas sim apresentar uma relação dialética, imprimindo também um conteúdo social a uma formação gerencial, apontando um rompimento com uma visão pragmática de adequação da qualificação ao trabalho, incorporando dimensões sociais, éticas, culturais e políticas.

Maturana (1999) defende que a aprendizagem é um processo coletivo, mas que tem significado individualmente. Então, cada um atribui significado ao conhecimento por meio do processo de aprendizagem, a partir de sua ontogenia e da relação com o outro, e é nessa interação que reconstruímos conhecimentos. Assim, para ensinar e aprender é preciso viver e conviver com o outro, relacionar-se e estabelecer vínculos de cooperação. Nessa perspectiva, acredita-se que o processo formativo gerencial precisa se efetivar em práticas andragógicas que possibilitem a problematização e a contextualização dos conhecimentos por meio de relações dialógicas, onde todos são coensinantes e coaprendentes, para que nessa relação possam transformar-se mutuamente.

Nesse contexto, este artigo procura identificar e discutir como está sendo oferecido o ensino gerencial aberto em IES do RS, mais especificamente os programas de pós-graduação lato sensu, MBA em Gestão Empresarial. Esta introdução é seguida de uma seção relacionada ao referencial teórico deste artigo, onde são sumarizadas as contribuições sobre pós- graduação lato sensu e formação gerencial. Logo a seguir, são apresentados os procedimentos metodológicos empregados para a coleta e análise dos dados, seguidos dos resultados obtidos e as discussões apontadas. Por fim, apresenta as conclusões dessa etapa da pesquisa e recomendações para a segunda etapa, e também estudos futuros sobre o tema. 


\section{Formação gerencial: discutindo conceitos}

Atualmente, há uma busca por programas que formem e capacitem gestores em vários níveis: graduação, pós-graduação (lato e strito sensu) e cursos de extensão oferecidos e com certificação por uma IES ou não, com o firme propósito de desenvolver novas competências gerenciais para gestores em exercício ou futuros gestores, promovendo a aprendizagem individual, adaptação organizacional e renovação (DOYLE, 1994; ANTONACOPOULOU, 2006; HAY e HODGKINSON 2008; RUAS e COMINI, 2007).

As investigações sobre formação e desempenho gerencial têm sido recorrentes na literatura acadêmica. Em uma visão panorâmica sobre a literatura da área, formação gerencial tem sido objeto de estudo tanto da área de negócios quanto da área educacional (BREWER e BREWER, 2010; CHOO, 2007; LOVE, 2006; MOSS, JEWITT, LEVAÃIÇ et al., 2007; CLOSS e ANTONELLO, 2010; PERIN, SAMPAIO, BECKER et al., 2009; ANTONELLO e RUAS, 2005). Nesse sentido, constata-se que existe uma carência de estudos que avaliem a efetividade da formação gerencial, principalmente na investigação entre "para que", "para quem" e "como" estes gestores aprendem. Também há a falta de referências norteadoras e metodológicas para avaliação e mensuração da efetividade desse tipo de formação (DIONNE, 1996; COLLINS, 2002).

Dessa forma, é reconhecido o esforço de pesquisadores em mapear e analisar características da formação gerencial e sua real efetividade, porém, por ser um tema abrangente e complexo, também se entende que ainda existe muito espaço para investigações que tratem desse assunto.

A investigação sobre formação gerencial tem versado sobre: (a) os aspectos conceituais da formação gerencial, que estudam a evolução conceitual dos termos e sua apropriação para o ambiente dos negócios (LUOMA, 2006; EBOLI, 2004; CLOSS e ANTONELLO, 2010); (b) os aspectos do processo da formação gerencial que dizem respeito à aprendizagem do nível gerencial e o seu desenvolvimento de competências para manter sua empregabilidade e conjuntamente a competitividade da organização (MOURA e BITENCOURT, 2006; RUAS, 2003; PERIN, SAMPAIO, BECKER et al., 2009); e (c), por fim, os aspectos relacionados ao mundo do trabalho que influenciam na formação gerencial, através das discussões sobre carreira e empregabilidade, enfatizando o aspecto educacional desse processo (ANTONELLO e RUAS, 2005; MINTZBERG e GOSLING, 2002; NICOLINE, 2003). Dentro dessa última vertente, é que é pesquisada a relação formação gerencial e IES, que, por razões de escopo, dar-se-á atenção aos estudos nacionais que tem examinado a relação entre formação gerencial e programas lato sensu (OLIVEIRA, 1996; RUAS, 2003; ANTONELLO e RUAS, 2005; FRESSATI e KASSAI, 2003). Antonacopoulou (2006) realiza uma importante discussão sobre a efetividade da formação gerencial, apontando aspectos importantes com relação à construção da identidade gerencial e como estes respondem à cultura de aprendizagem e desenvolvimento do local em que se encontram.

Fazendo uma síntese de alguns estudos, Oliveira (1996) discute sobre o redesenho de um programa de MBA de uma IES privada, apresentando um formato inovador para a formação gerencial. Ruas (2003), por outro lado, introduz o tema competências para a formação gerencial, pensando na prática como os programas formais das IES podem incluir e gerar novas competências para os gestores. Antonello e Ruas (2005) propõem uma análise da efetividade dos programas de pós-graduação lato sensu e a questão da aprendizagem na ação como forma de articular teoria e prática. Por fim, Fressati e Kassai (2003) contribuem para essa discussão, analisando o impacto de um curso dessa modalidade para a carreira dos egressos. O que esses artigos têm em comum é sua discussão sobre a real efetividade de um programa de pós-graduação na formação e carreira dos egressos. Herrington e Radford (2010) propõem uma interessante reflexão sobre o passado, presente e futuro dos cursos de MBA, destacando o crescimento vertiginoso desses programas no século XX. Esses autores apontam que existe, atualmente, uma saturação comercial desse tipo de educação gerencial, faltando uma real demonstração da efetividade do que é oferecido.

Em um mundo plano (FRIEDMAN, 2009), onde a mudança tem sido rápida e profunda ao mesmo tempo, contata-se que a década de 90 do século passado representou para os estudos sobre formação gerencial um período de grandes mudanças. Souza (2010) cita quatro elementos que passaram a fazer parte do cotidiano 
dos gestores, sendo eles: (a) velocidade e o caráter universal da informação; (b) constante mutação dos padrões de consumo, que interferem nos processos de gestão; (c) impacto dos temas políticos globais sobre a vida; e (d) emergência da questão ambiental.

Esses elementos aumentaram a complexidade da função e ação gerencial, que segundo Motta (2000), o dirigente necessita tanto da arte quanto da ciência nesse papel. Dessa forma, ser gerente é exercer um papel peculiar entre a ação e a concepção (DAVEL e MELLO, 2005), deparando-se com tarefas transformacionais complexas, como aprender o que é ser um gestor, ter julgamentos interpessoais, lidar com pressões da função e obter novos conhecimentos (HILL, 1999).

Em um estudo sobre relações de trabalho e ação gerencial, Maciel e Silva (2012, p. 25) comentam que "o contexto e os fatores determinantes da prática indicam que as transformações ocorridas na organização afetaram a maneira de agir do gerente no contexto de sua ação profissional". Em outras palavras, a noção de qualificação para a função não consegue mais dar conta desse novo contexto em que os gerentes assumem seus cargos e tarefas.

Nesse processo, a educação passa a desempenhar um papel importante na formação de um gestor, pois além de capacitar as pessoas com recursos operacionais para a resolução de problemas e a tomada de decisão no dia a dia, formar um gestor também é "permitir e facilitar o crescimento das pessoas como ser humano" (MATURANA e REZEPKA, 2008, p.13), desenvolvendo competências técnicas, humanas e políticas. A formação oferece condições de fazer com que este gestor amplie sua capacidade de ação e reflexão no mundo em que vive. Demo (1996; 1999) preconiza que uma educação de qualidade é aquela que ultrapassa os fragmentos do ensino disciplinar, cultivando o espaço da dúvida, favorecendo a construção de projetos inovadores e o desenvolvimento de competências, em uma dimensão de qualidade formal e também de qualidade política.

Essa problemática com relação à formação gerencial no mundo contemporâneo apresenta-se como um desafio para as IES, porque a universidade vive uma situação complexa, onde ela "não parece estar preparada para defrontar os desafios" (SANTOS, 2010, p.187) e as exigências da sociedade e das organizações, pois seus problemas remetem à questão estrutural, na medida em que "a perenidade da instituição universitária, sobretudo no mundo ocidental, está associada à rigidez funcional e organizacional, à relativa impermeabilidade às pressões externas, enfim, aversão à mudança" (SANTOS, 2010, p. 187). Esse autor traz a necessidade premente de rever os modelos de atuação universitária e os produtos e serviços oferecidos, seja no âmbito da graduação ou da pós-graduação, em uma sociedade que não aceita mais a produção e reprodução de conhecimento e que, segundo Buarque (1994), a universidade como produtora de conhecimento não pode mais passar ao largo das novas ideias e mudanças que se operam em torno dela.

A dimensão profissionalizante da educação superior discute a atualidade e efetividade dos programas de pósgraduação lato sensu, que se desdobram em cursos de aperfeiçoamento ou especialização, sendo a tendência mais recente no âmbito dos stricto sensu, os mestrados profissionalizantes. O ponto a ser destacado é "saber se o conteúdo da formação que é dado pelo sistema universitário brasileiro está sendo compatível com as demandas da sociedade" (SANTOS, TEIXEIRA, RIBEIRO et al., 2007, p. 491), mais especificamente com as demandas para a formação gerencial. A orientação basilar atual para os projetos pedagógicos de cursos é o desenvolvimento de competências em contraposição à noção de qualificação.

As noções de competência e qualificação se distinguem, porque essas "expressões [...] ocupam lugares de destaque nos discursos e documentos dos diferentes agentes e instituições sociais" (MANFREDI, 1998, p.14). A problemática da qualificação sempre esteve no centro de análise sobre o mundo produtivo, mas a noção de competência assume um caráter contemporâneo. Entretanto, é inegável que são conceitos complexos e polêmicos. Manfredi (1998) argumenta que a epistemologia de análise desses conceitos é distinta, pois a noção de qualificação está mais associada ao repertório das ciências sociais e à noção de competência, ancorada nas abordagens das ciências humanas. 
Em primeiro lugar, toma-se a compreensão da noção de qualificação, que se ancora nas questões do capital humano e a preocupação com o nível educacional e formativo do contingente de trabalhadores. As discussões sobre a necessidade de qualificação do sistema educacional não são novas. Estudos da UNESCO já apontavam para uma necessidade de revisão e atualização dos indicadores de qualidade da educação na América Latina (PAIVA, 1993). Essas discussões surgiram principalmente devido à necessidade de posicionar a educação frente a um novo papel em uma agenda de modernidade, onde a qualificação do contingente humano fazia-se necessária. Várias publicações da década de 90 do século passado (PAIVA, 1994; 1993; MELLO, 1993; NEVES, 1993; GITAHI e RABELLO, 1993; FERREIRA, 1992) começaram a apontar o conceito de qualificações-chave necessárias para que as empresas e os trabalhadores pudessem dar conta das exigências descritas pela nova configuração das mudanças, especificando que, para as mutações do mundo do trabalho, essas qualificações poderiam garantir uma vaga no mercado de trabalho. No caso gerencial, garantiriam o acesso a cargos e funções com predomínio pelo papel gerencial, tais como coordenadores, supervisores, gerentes e diretores.

As noções de qualificação serviram de parâmetros e pressupostos em um modelo de organização do trabalho do tipo taylorista-fordista, e tendo como pressupostos as descrições de uma matriz de cargos e funções.

Essa concepção de qualificação tem como matriz o modelo job/skills definido a partir da posição a ser ocupada no processo de trabalho e previamente estabelecida nas normas organizacionais da empresa, de acordo com a lógica do modelo taylorista/fordista de organização do trabalho. Na ótica desse modelo, a qualificação é concebida como sendo "adstrita" ao posto de trabalho, e não como um conjunto de atributos inerentes ao trabalhador (MANFREDI, 1998, p.18).

Notoriamente, o conceito de qualificação se constrói e consolida dentro de um modelo específico de organização do trabalho (taylorista-fordista), gerando diretrizes para a área de gestão de pessoas sobre carreira, emprego e remuneração. Assim, diante desse debate conceitual, como entender a inserção da noção de competência no mundo organizacional e educacional? Caruso e Pero (1996) lembram que para o enfrentamento do processo de obsolescência do saber, a educação gerencial passa a ser mais um desafio para as empresas, necessitando, agora, mobilizar novas competências, com implicações para as relações de trabalho e também as políticas de gestão de pessoas. Nesse sentido, passa-se a valorizar o que está além do prescrito para o cargo, mobilizando dimensões de saber-fazer, saber-agir e do saber-ser (LE BOTERF, 2003; ZARIFIAN, 2001).

A noção de competência ainda é uma definição em construção, porém, em um contexto contemporâneo, o termo competência pode designar "repertórios de comportamentos e capacitações que algumas pessoas ou organizações dominam melhor que outras, fazendo-as eficazes em uma determinada situação" (LEVYLEBOYER, 1996, p.54). No Brasil, a noção e o uso do termo competência ganha força no final dos anos 90, passando a incorporar os discursos empresariais, educacionais e de formação do trabalhador.

Nessa definição de competência, existe um pressuposto de que deverá haver uma capacidade de transferência, de aprendizagem e de adaptação do trabalhador às situações novas e imprevistas (LE BOTERF, 2003), envolvendo, além dos conhecimentos formais para o desempenho das atividades, um saberfazer, que se refere à prática cotidiana de uma profissão; o saber-ser, que mobiliza estratégias (esquemas interpretativos e modelos mentais) para compreensão do mundo social; e um saber-agir, que se distingue pela ação do comportamento nas várias situações de trabalho.

Um ponto a ser abordado diz respeito ao deslocamento do fazer (qualificação) para o saber fazer e saber agir (competência). Com relação a isso, Ruas $(2003$, p. 7) comenta que "a efetividade dos processos de mudança estariam associados à revisão e ao desenvolvimento da maneira de pensar e atuar dos gestores, expressão essa muito próxima da noção de competência [...]”. Esse autor salienta que a adoção de uma das abordagens existentes sobre competências no âmbito gerencial deve ser definida de acordo com os objetivos de sua 
aplicação, e não como uma decisão teórica. Isso poderia pautar o desenvolvimento dos programas de formação gerencial oferecidos pelas IES.

Essa concepção é também reforçada por Le Boterf ao mencionar que: "o que irá diferenciar a competência de uma empresa ou de uma unidade (divisão, departamento, serviço) não é a competência de seus membros. $\mathrm{O}$ diferencial não depende tanto de seus elementos, mas da qualidade da combinação ou articulação entre seus elementos" (LE BOTERF, 2003, p. 22).

No âmbito educacional, para o desenvolvimento da noção de qualificação, as alternativas mais empregadas estavam relacionadas com sistemáticas de formação formal, como cursos, seminários, palestras e workshops, com um enfoque na dimensão conhecimento. Já para o desenvolvimento de competências, além das estratégias citadas, foram adicionados os jogos, simulações, vivências, estudos de caso, entre outras. Porém, essas abordagens acabavam sempre remetendo ao desenvolvimento de novas competências para um ambiente simulado ou artificial, não atingindo os problemas gerenciais do cotidiano organizacional.

Assim, esse estudo parte do pressuposto de que a formação gerencial precisa ser uma busca, tanto da organização quanto do indivíduo, independentemente do local em que a mesma aconteça. Também se entende que a efetividade do desempenho gerencial acontecerá na medida em que houver mobilização de novos esquemas interpretativos por parte dos gestores sobre seu papel e atividade no mundo organizacional contemporâneo. Acrescido a isso, a formação gerencial necessita ser revisitada pelas IES, através de programas de pós-graduação, com currículos atualizados, tanto no conteúdo quanto na metodologia, destacando o desenvolvimento de novas competências, tanto na teoria quanto na prática gerencial, pois "a aquisição de conhecimento ocorre em qualquer lugar, a qualquer hora na sociedade interligada, em rede, não linear, nem previsível, incompatível com a ideia de caminhar do mais fácil para o mais difícil" (SCHELEMMER, 2002, p. 146).

\section{Pós-graduação Lato Sensu: Os Programas de MBAs}

O segmento da pós-graduação lato sensu e os mestrados profissionalizantes se estruturam em velocidade crescente, mesmo com um controle mais efetivo da CAPES (SANTOS, TEIXEIRA, RIBEIRO et al., 2007). No Brasil, as especializações foram criadas na década de 60 do século passado, com o intuito de qualificar o processo de formação profissional, complementando os estudos da graduação. A partir da década de 90, a crescente busca de qualificação da força de trabalho e sua reciclagem promoveu uma busca intensa pelos mais diversos tipos de programas de formação e educação, que, ao invés de ser um complemento à graduação, volta-se para a possibilidade de ampliar a empregabilidade do profissional. Esse é um dos argumentos utilizados pelas IES para a disseminação e venda de programas de pós-graduação lato sensu, mais especificamente os chamados MBAs. Os cursos de especialização em nível de pós-graduação lato sensu presenciais (nos quais se incluem os cursos designados como MBA), oferecidos por IES, independem de autorização, reconhecimento e renovação de reconhecimento, devendo obedecer a resolução CNE/CES $n^{\circ} 1$, de 08 de junho de 2007.

Nesse cenário, os cursos de pós-graduação assumiram um papel importante e estratégico, observado pelo crescimento e busca desse tipo de formação no mundo (BARUCH e PEIPERL, 2000; FREZATTI e KASSAI, 2003) e no Brasil. Dados da Associação Nacional dos MBA (ANAMBA) indicam que a procura pela oferta desse tipo específico de produto educacional tem aumentado em 5\% ao ano, sendo que essa mesma associação estima que atualmente existam cerca de 9 mil cursos de MBA no Brasil.

Os MBAs apresentam-se como um tema de pesquisa para várias disciplinas (BARUCH e PEIPERL, 2000; ASCHER, 2000; MINTZBERG e LAMPEL, 2001; WOOD Jr., 2001; FREZATTI e KASSAI, 2003; SCOTT, 2001). 
Diversos estudos apontam as razões para a busca de um MBA por um profissional, sendo as mais citadas: ampliação das oportunidades de mercado e carreira; mudança no perfil de competências para a carreira; obter noções sobre negócios; e ampliar os conhecimentos intelectuais sobre um assunto (BARUCH e PEIPERL, 2000; ASCHER, 2000; LUKER, 1989). Uma pesquisa divulgada recentemente pela ANAMBA (2011) sobre o perfil, expectativas e percepção de qualidade dos programas de MBA revelaram que: (a) $67 \%$ dos estudantes têm entre 28 a 38 anos; (b) 62\% do nível hierárquico dos alunos desse tipo de programa se encontra no segundo e terceiros escalões; (c) $52 \%$ trabalham em empresas de grande porte; (d) que com relação à modalidade de pagamento, 54\% pagam integralmente ou parcialmente seus estudos; (e) nos motivos apresentados para cursar um programa desse tipo, $92 \%$ indicam a busca de novos conhecimentos e formação de networking; e (f) $71 \%$ escolhem o local em que farão o programa devido a fatores como tradição da escola e do curso.

Por outro lado, atualmente existem rankings que analisam e indicam cursos para o público em geral, tipo Guia Você S.A. ou publicações de jornais (Folha de São Paulo ou jornal Zero Hora/RS), que mesmo tendo uma abrangência de divulgação, a metodologia empregada muitas vezes é discutida nos meios acadêmicos (FREZATTI e KASSAI, 2003). As pesquisas acadêmicas sobre o assunto discutem desde questões relacionadas ao ensino à distância (SCOTT, 2001), as questões relacionadas à carreira (BARUCH e PEIPERL, 2000), o desenvolvimento de competências e aprendizagens (ANTONELLO e RUAS, 2005), o impacto de um programa de MBA na evolução profissional (FREZATTI e KASSAI, 2003).

Porém, existem críticos (MINTZBERG e LAMPEL, 2001; WOOD Jr., 2001) a esse tipo de formação, destacando que muitos empresários de sucesso não buscam um MBA para dar um upgrade nas suas carreiras e que o conceito de um programa de MBA nem sempre foi bem compreendido no Brasil, já que nosso país muitas vezes replica nomes, modas e modismos sem uma devida interpretação para o contexto brasileiro.

Assim, ainda existem lacunas e um campo fértil para pesquisa sobre esse tema, que, ao contrário de ter se esgotado, parece-nos que está apenas iniciando os debates sobre sua real efetividade para o desenvolvimento de competências na formação gerencial.

\section{Procedimentos metodológicos}

Uma das estratégias orientadoras desse estudo é caracterizada pelo método qualitativo. Justifica-se a escolha desse método, pois segundo Marshall e Rossman (1999), os métodos qualitativos são apropriados para gêneros de pesquisas que são remetidos ao seu ambiente natural e com aproximações exploratórias de dados. Esse estudo também pode ser classificado como exploratório, por proporcionar uma maior flexibilidade na busca de informações sobre um determinado problema ou investigação, com vistas a torná-lo mais claro, seja na construção de novas hipóteses, seja no aprimoramento de ideias sobre o tema (GIL, 1989).

Como esse estudo é um recorte de um projeto de pesquisa com duração de dois anos, o mesmo foi dividido no que se denominou "momentos da pesquisa". Aqui, é apresentado o chamado "momento um", representando o primeiro e segundo ano da mesma (2011-2012). O desenho da pesquisa previa a realização de um mapeamento do ensino gerencial oferecido por IES, públicas ou privadas, do RS. O objetivo principal foi o de identificar os tipos de produtos e serviços oferecidos para a formação gerencial. Consideraram-se os programas de pós-graduação lato sensu, mais especificamente MBA em Gestão Empresarial. A escolha desta modalidade de MBA não foi aleatória, e sim intencional, pois foi compreendida pela pesquisadora como um espaço de formação em que profissionais de várias profissões e categorias buscam uma compreensão sobre o que é gestão e o que é ser um gestor.

A coleta de dados aconteceu através de dados primários e secundários. A primeira estratégia de coleta de dados foi a dos dados secundários, que consistiu na visita aos sites das IES do RS, obtidos através de relatórios fornecidos pelo Instituto Nacional de Ensino e Pesquisa (INEP). Para atingir os objetivos da 
pesquisa foram selecionadas quinze IES (quadro 1), 1 pública e 14 privadas, que tinham programas de pósgraduação lato sensu, do tipo MBA em Gestão Empresarial.

Após essa escolha foi realizada uma primeira visita ao site das IES escolhidas, coletando dados sobre sua localização, as principais descrições sobre o objetivo do programa e seus diferenciais.

\section{Quadro 1}

Identificação das IES pesquisadas

\begin{tabular}{|l|l|c|c|}
\hline \multicolumn{1}{|c|}{ IES } & \multicolumn{1}{|c|}{ Região RS } & Pública & Privada \\
\hline IES 1 & Porto Alegre & $\mathrm{X}$ & \\
\hline IES 2 & Novo Hamburgo & & $\mathrm{X}$ \\
\hline IES3 & Cachoeirinha & & $\mathrm{X}$ \\
\hline IES4 & Porto Alegre & & $\mathrm{X}$ \\
\hline IES5 & Porto Alegre & & $\mathrm{X}$ \\
\hline IES6 & São Leopoldo & & $\mathrm{X}$ \\
\hline IES7 & Porto Alegre & & $\mathrm{X}$ \\
\hline IES 8 & Três de Maio & & $\mathrm{X}$ \\
\hline IES9 & Santa Cruz do Sul & & $\mathrm{X}$ \\
\hline IES 10 & Canoas & & $\mathrm{X}$ \\
\hline IES 11 & Lajeado & & $\mathrm{X}$ \\
\hline IES 12 & Pelotas & & $\mathrm{X}$ \\
\hline IES 13 & Porto Alegre & & $\mathrm{X}$ \\
\hline IES 14 & Porto Alegre & & $\mathrm{X}$ \\
\hline IES 15 & Porto Alegre & & $\mathrm{X}$ \\
\hline
\end{tabular}

Fonte: Dados da pesquisa.

Foram enviados e-mails, nos meses de junho a setembro de 2011, para todos os contatos que eram indicados no site (falar com o coordenador), apresentando a pesquisa e o convidando para uma entrevista. Das 15 instituições elencadas, 5 coordenadores se prontificaram a participar (quadro2), compondo as entrevistas individuais em profundidade. As 5 IES que participaram da pesquisa disponibilizaram documentos como folders do curso e algumas, os seus projetos pedagógicos.

Quadro 2

\section{Perfil dos coordenadores entrevistados}

\begin{tabular}{|c|c|l|l|}
\hline Coordenador & IES & \multicolumn{1}{|c|}{ Formação Escolar } & \multicolumn{1}{c|}{ Inserção na coordenação } \\
\hline C1 & IES 10 & Especialista em Logística & Trabalha há 10 anos na IES e está há 8 meses como coordenador. \\
\hline C2 & IES 8 & Mestre em Engenharia da Produção & Coordena o curso desde 2004. \\
\hline C3 & IES 7 & Doutor em Engenharia da Produção & É diretor acadêmico, assumindo a coordenação da pós conjuntamente. \\
\hline C4 & IES 6 & Doutor em Psicologia & Coordena o curso desde 2011 \\
\hline C5 & IES 9 & Mestre em Administração & Coordena o curso desde 2005. \\
\hline
\end{tabular}

Fonte: Dados da pesquisa. 
Os dados secundários compuseram a construção de um corpus documental que foram considerados como fontes de pesquisa. Em sua análise, lançou mão de referências da análise historiográfica, que é a produção de conhecimento histórico, isso porque, como diz Le Goff (2001, p. 54) "o documento não é inocente, não decorre apenas da escolha do historiador, ele próprio é parcialmente determinado por sua época e seu meio [...] ao mesmo tempo, é preciso delimitar, explicar lacunas, os silêncios da história, e assentá-la tanto sobre esses vazios quanto sobre os cheios que sobreviveram".

Deve-se ressaltar aqui que uma análise historiográfica de documentos não é apenas uma montagem históricados documentos coletados, mas, antes de tudo, os documentos arquivados e dispostos à consulta são um legado de um determinado modo de arquivar, selecionar e dispor, que podem ser justificados tanto pelo critério econômico - custos para manutenção de documentos - quanto pela impossibilidade de guarda de todos os documentos, mas, mesmo assim, essa guarda remete a uma época e história que o produziram (LE GOFF, 2001).

Com relação aos dados primários, foram realizados dois tipos de entrevistas semiestruturadas com questões padrões abertas. Uma com os coordenadores das cinco IES participantes da pesquisa (quadro 2) e também foram entrevistados 6 especialistas em formação gerencial (quadro 3), escolhidos por afinidade de relacionamento, utilizando-se a amostragem por julgamento (MALHOTRA, 2001).

\section{Quadro 3}

Perfil dos especialistas entrevistados.

\begin{tabular}{|c|c|l|}
\hline Entrevistado & Trabalho & \multicolumn{1}{c|}{ Formação Escolar } \\
\hline P1 & Consultoria & Mestrado em Educação. \\
\hline P2 & Consultoria & $\begin{array}{l}\text { Curso superior completo e pós-graduação em Gestão } \\
\text { Estratégica de Pessoas. }\end{array}$ \\
\hline P3 & Consultoria & $\begin{array}{l}\text { Graduação em Administração, MBA em Gestão Empresarial e } \\
\text { Mestrado em Administração. }\end{array}$ \\
\hline P4 & $\begin{array}{c}\text { Professor de MBA e e } \\
\text { consultoria }\end{array}$ & $\begin{array}{l}\text { Graduação em Psicologia, Especialização em Recursos } \\
\text { Humanos e Especialização em Psicologia da Comunicação. }\end{array}$ \\
\hline P5 & IES & $\begin{array}{l}\text { Graduação em Engenharia Mecânica, Especialização em } \\
\text { relação universidade X empresa e Mestrado em Engenharia de } \\
\text { Energia e iniciou Doutorado em Engenharia da Produção. }\end{array}$ \\
\hline P6 & Consultoria & $\begin{array}{l}\text { Graduação em Administração e pós-graduação em Gestão do } \\
\text { Capital Humano. }\end{array}$ \\
\hline
\end{tabular}

Fonte: Dados da pesquisa.

Acertada a seleção final dos sujeitos a serem entrevistados, foram agendados os horários e realizadas as entrevistas, de forma individual e pessoal pela pesquisadora. As entrevistas ocorreram no período de agosto a dezembro de 2011. Em média, cada entrevista teve a duração de 60 minutos e, mesmo que seguissem um tópico-guia, perguntas adicionais foram realizadas para um melhor entendimento e/ou esclarecimentos das opiniões e percepções dos coordenadores e especialistas (VERGARA, 2007). Essas entrevistas foram transcritas e revisadas pelos entrevistados e pesquisadora, constituindo textos digitados, que foram objetos de análise.

Com relação à análise das entrevistas realizadas, considerou que as entrevistas também representam um texto em que "as falas referem-se aos pensamentos, sentimentos, memórias, planos e discussões das pessoas, e 
algumas vezes nos dizem mais do que seus autores imaginam" (BAUER e AARTS, 2002, p. 189). Assim, após a transcrição, o corpus documental foi analisado no seu conteúdo e, como sugere Flick (2004), empregam-se categorias estabelecidas em uma combinação de quadro teórico e dos dados do campo.

Para a apresentação dos dados, foram gerados mapas que adotaram a ideia proposta por Deluze e Guatarri (1995), uma vez que os mapas apresentam modos de reconfigurar o corpus documental, produzindo análises específicas dos locais e sujeitos entrevistados, sendo um exercício de análise, ancorado no real, não reproduzindo elementos fechados em si mesmos, mas sim, em permanente construção e desconstrução dos dados, que auxiliam posteriormente a compreender as percepções do entrevistados.

Por fim, o processo de interpretação e reinterpretação foi alicerçado em todos os momentos descritos anteriormente e a interpretação implicou em um novo pensamento sobre o objeto de estudo através de construções de possíveis significados (THOMPSON, 1995), mesmo porque esse processo de interpretação não foi estanque, ocorrendo durante todo o processo de pesquisa. Nesse sentido, procurou-se ir além da mera descrição de fatos e dados, acrescentando algo à discussão do fenômeno estudado, apontando caminhos alternativos e estabelecendo relações entre o que existia, existe e poderá existir, na busca de novas indagações a serem exploradas em estudos futuros.

\section{Apresentação e Análise dos Dados}

Para a apresentação e análise dos dados, optou-se por dividir a apresentação em duas partes, sendo elas: (a) uma análise da atual oferta de produtos e serviços, com relação à pós-graduação lato sensu, mais especificamente MBA em Gestão Empresarial oferecidos por Instituições de Ensino Superior, privadas e públicas, do Estado do Rio Grande do Sul; e (b) a percepção dos coordenadores e especialistas sobre essa oferta.

\section{A oferta de produtos e serviços da pós-graduação lato sensu}

A primeira informação com relação à oferta ou demanda por produtos e serviços de pós-graduação lato sensu em formação gerencial é encontrada nos sites das IES pesquisadas (quadro 1). Das 15 IES pesquisadas, somente uma pertence à esfera pública, sendo as demais do âmbito privado, onde 8 não são filantrópicas, ou seja, atuam no ensino superior como uma opção de negócio.

No Brasil, apesar das IES de cunho privado não serem objeto sistemático de estudo e pesquisa, nota-se que um crescente número de IES do setor privado tem predominado. Segundo dados do INEP, as IES privadas já respondem por mais de $85 \%$ do total das IES do Brasil (KARAWEJCZYK, 2005). O movimento para a criação de universidades privadas é recente e tomou forma a partir da Lei de Diretrizes e Bases da Educação (LDB) de 1996.

Esses dados corroboram os indicativos apontados para o crescimento da oferta de produtos e serviços em formação gerencial no País (FREZATTI e KASSAI, 2003), principalmente na esfera privada. Tanto Lobo Filho (1996) quanto Demo (1993) já discutiam o papel estratégico das IES privadas na formação do contingente de trabalhadores de modo geral, onde a universidade seria uma instituição que estaria na vanguarda do desenvolvimento, produzindo mudanças sociais e sinalizando rumos e novas oportunidades.

Outra informação retirada dos documentos das IES diz respeito a uma falta de clareza entre os produtos e serviços oferecidos na pós-graduação, afinal: é especialização ou MBA? Apesar de essas duas modalidades serem consideradas cursos lato sensu, os programas de MBA apresentam-se como um curso voltado para o público executivo que busca ampliar suas competências sobre sua atuação (BARUCH e PEIPERL, 2000), 
com um formato distinto de um programa de especialização, principalmente na metodologia, com a utilização do método do caso. O trecho retirado da fala de um dos coordenadores demonstra isso.

[...] tínhamos a especialização em gestão empresarial, aí surgiu, acho que há uns 10 anos, alguma coisa, um movimento do MBA e naquela época eu lembro que eu fui pesquisar alguma coisa sobre o MBA, quais as características do que devia contemplar e me pareceu que ele teria que ter uma condição mais prática, mais aplicável do que apenas aquela referência acadêmica. Só, então, o termo aplicabilidade ter essa inserção com organizações e alguma coisa nesse sentido. Mas foi em cima disso aí, aí foi mudado o termo pra MBA (Entrevista C5, 2011).

Esse relato exemplifica as confusões de terminologia que ocorrem na pós-graduação lato sensu. Santos, Teixeira, Ribeiro et al.(2007) defende que investir em especializações como instrumento complementar à formação da graduação, ampliando a capacitação dos discentes, não se justifica atualmente.

A falta de uma distinção clara para as IES sobre esse assunto vai ao encontro do que Wood Jr. (2001) apresenta como crítica, ou seja, as réplicas de nomes e conceitos importados, relacionados à gestão e nem sempre bem compreendidos na realidade brasileira. Este fato também pode gerar percepções mercadológicas equivocadas no oferecimento desse tipo de produto, pois o público-alvo, tendo acesso às mais variadas mídias, busca através dos sites das IES um esclarecimento inicial sobre onde cursar (instituições) e o que cursar.

Nesse ponto, Ruas (2003) defende que não basta a participação dos gestores em programas formais que visem à educação gerencial, mas é necessário entrelaçar estes programas com processos de transferência e mobilização do conjunto de conhecimentos e habilidades para o ambiente de trabalho.

Complementado essa análise, construiu-se o primeiro mapa (figura 1), intitulado "Os objetivos dos MBAs em gestão empresarial no RS”, produzido com dados encontrados nos sites das IES.

Figura 1

\section{Mapa 1 - Objetivos do MBA}

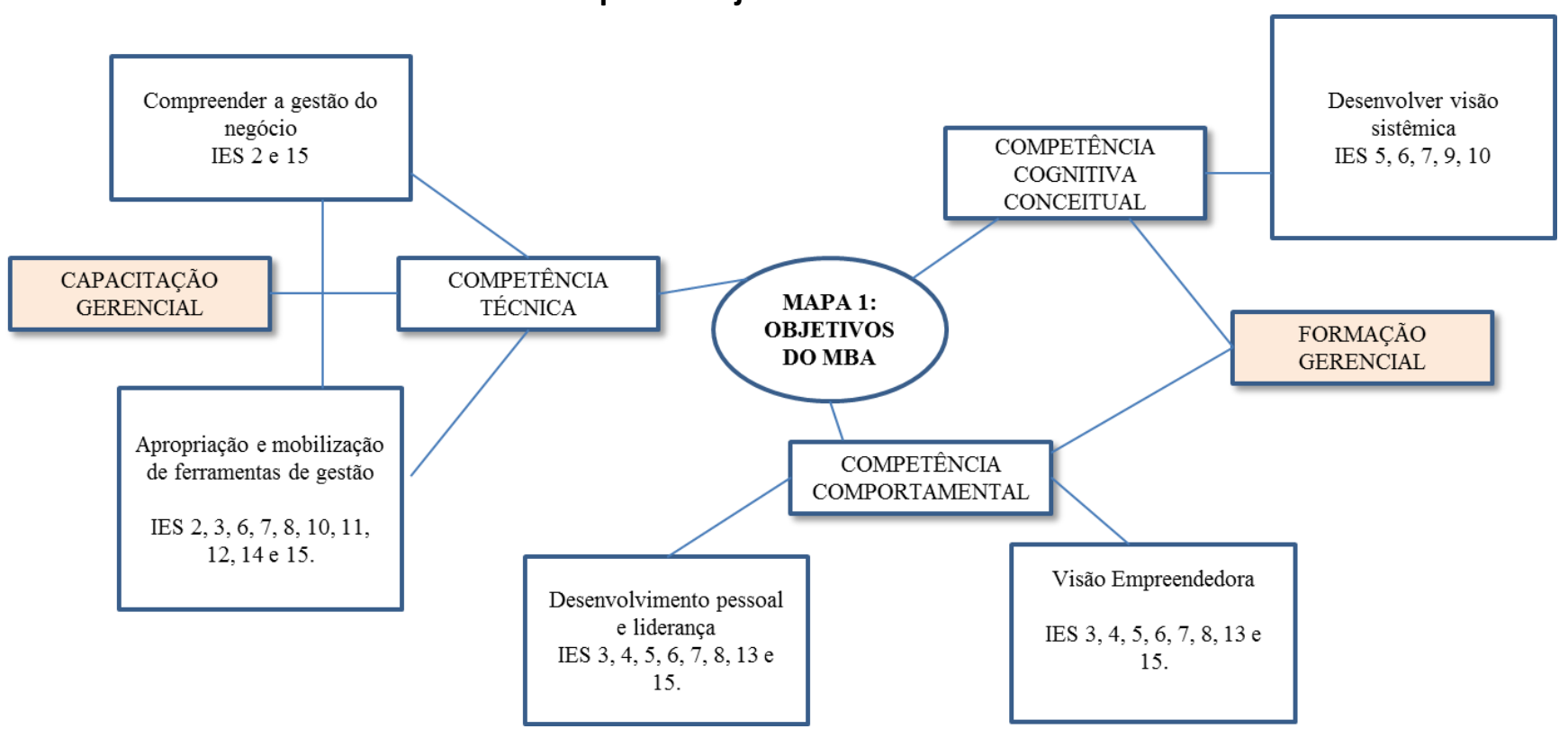

Fonte: Dados da pesquisa. 
Analisando o mapa 1 sobre os objetivos de um MBA, ele se inicia pelas competências dos egressos, ou seja, o que é oferecido como diferencial em um MBA. Os programas que participaram desse estudo são voltados para suprir lacunas dos egressos da graduação, nas competências conceituais, comportamentais e técnicas dentro do que seria preconizado para uma formação gerencial.

Em um estudo sobre o trabalho gerencial, Mintzberg (1973) também concluiu que os gerentes deveriam desempenhar papéis relacionados a essas três esferas, ou seja, a interpessoal (comportamental), informacional (técnica) e decisório (conceitual), agregando maior valor à ação gerencial. Porém, as pesquisas de Motta (2000, p. 27) já apontavam que o aprendizado e domínio de habilidades técnicas e/ou comportamentais não seriam suficientes para a formação de um gestor, pois "capacidade gerencial é mais rara, pois exige habilidades mais complexas: capacidade analítica, de julgamento, de decisão e liderança, e enfrentar riscos e incertezas [...] sendo que estas capacidades só se conseguem através de aprendizado gerencial na prática".

O que chama a atenção na figura 3 é a falta de conteúdos relacionados à ética, valores, o saber-agir, crenças e tantos outros elementos que tornam o aprendiz como sujeito coensinante e coaprendente da sua própria formação. Para Maturana e Varela (2002) e Maturana (1999), a configuração do espaço de convivência na formação de uma pessoa ocorre quando o ser humano representa sua percepção e perspectiva, considera legítima a representação do outro, estabelece perturbação entre as diferentes representações e compensa essa perturbação na construção de novas representações, em congruência com o meio na qual está inserido.

Isso somente é possível quando o ensino gerencial tornar-se mais formação e menos capacitação para a empregabilidade. Nesse sentido, o entendimento da pesquisadora é que o oferecido pelos MBAs ainda se situa em um contexto com uma abordagem mais formal e tradicional. Burgoyne e Stuart (1991) indicavam que, no início dos anos 90 do século passado, a entrega da educação gerencial era mais funcionalista em termos de conceitos do que de prática vivenciada e aprendida.

\section{A percepção dos coordenadores e especialistas sobre a oferta de produtos e serviços da pós-graduação lato sensu}

O papel do coordenador de um curso de pós-graduação seria o de implementar o curso no seu dia a dia. O mapa 2 (figura 2) foi produzido a partir dos dados coletados nas entrevistas com os cinco coordenadores. 
Figura 2

\section{Mapa 2 - Percepção dos coordenadores}

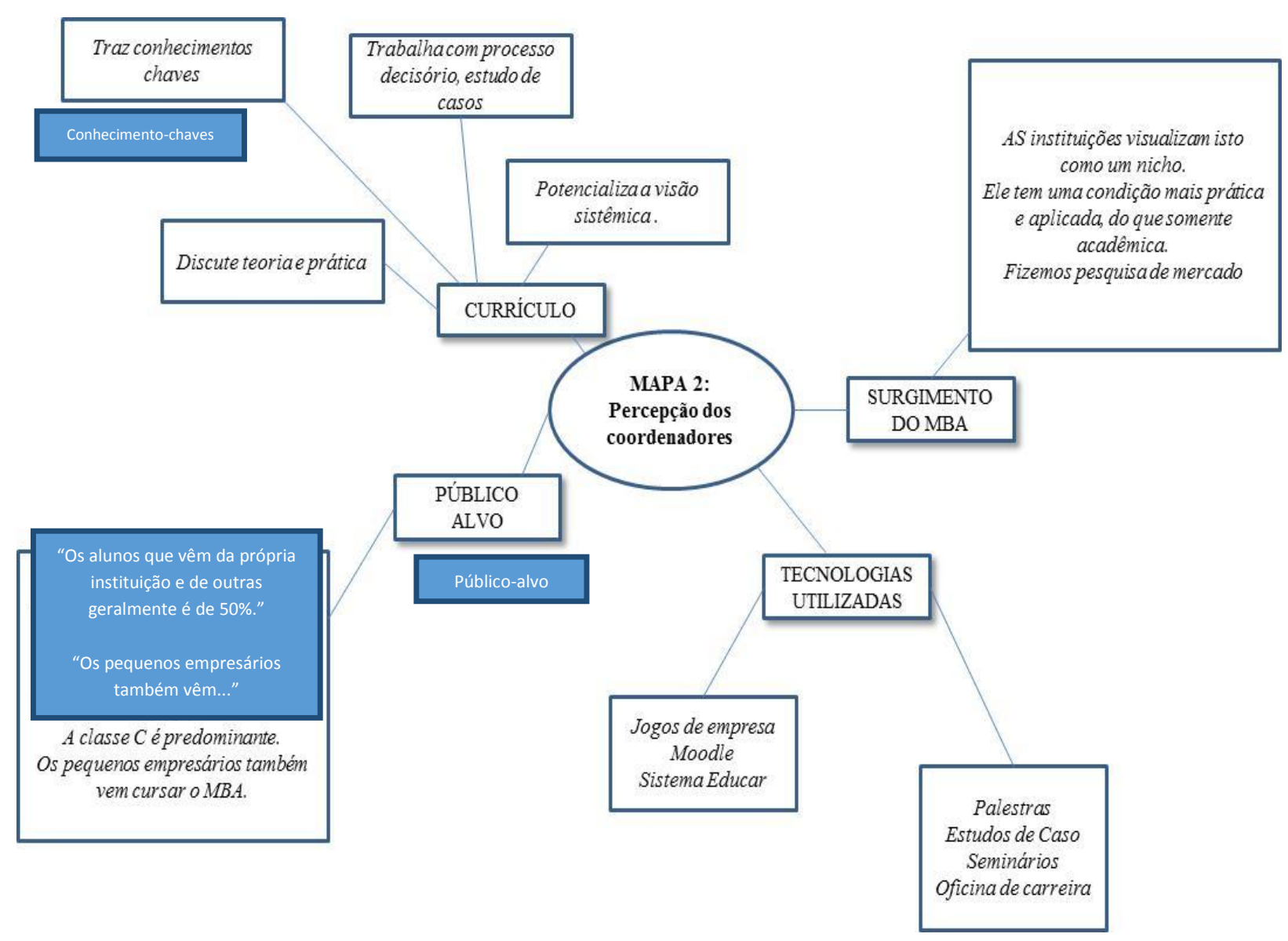

Fonte: Dados da pesquisa.

A primeira variável a ser analisada é o surgimento desse tipo de programa em uma IES. Os coordenadores entrevistados consideram que a busca por qualificação gerencial aumentou por vários motivos: (a) o próprio reconhecimento de ter um certificado de uma IES reconhecida no mercado de trabalho; (b) proporcionar um upgrade na carreira profissional; (c) muitos gestores não têm como formação de base um curso de administração e vêm buscar o MBA para ampliar competências.

Seguem alguns trechos das falas dos coordenadores que expressam isso: "eu vejo o MBA com esse foco bem Lato Sensu, assim ele tem que desenvolver capacidades de atualização" (Entrevista C4, 2011). [...] "Vem muito mais em busca de elementos como liderança, como disseste formação de equipe e atualização de conhecimentos em área, por exemplo, como Marketing, Logística, própria questão estrutural e gerencial" (Entrevista C5, 2011).

Importante a ser observado é que ainda faltam pesquisas de mercado para identificar as próprias necessidades gerenciais. Uma das explicações possíveis é que os coordenadores de uma IES que oferece um MBA na área de Gestão Empresarial, geralmente, são oriundos do mercado de trabalho, como consultores ou gestores, e assim, há um pressuposto que estes sabem o que é esperado para esse tipo de programa, utilizando sua experiência profissional e também percepções e insigths na construção do currículo. 
Uma segunda variável a ser analisada são os próprios currículos desses programas e as tecnologias e ferramentas utilizadas. A concepção do projeto político-pedagógico de um curso deve refletir as competências que o egresso deveria ter ao terminar sua formação acadêmica. A concepção curricular não é somente um dispositivo de disciplinas e seminários alocados em um determinado espaço-tempo, porque, dessa forma, "[...] o conjunto daquilo que se ensina e daquilo que se aprende, de acordo com uma ordem de progressão determinada, no quadro de um determinado ciclo de estudos" (FORQUIN, 1996, p.188), gerando a fragmentação do currículo em disciplinas ou núcleo de matérias. Mesmo que o currículo seja uma forma de prescrever o que deve ser ensinado no sentido de homogeneizar, igualar, regular e normatizar os saberes escolares dentro do sistema educativo, a concepção inovadora e contemporânea de currículo, em tempos multiculturais e midiáticos, deixa de responder o quê, como, quando e quais os melhores meios e os resultados obtidos, e passa a questionar os saberes hierarquizados e fragmentados, procurando elaborar um currículo local, para um determinado grupo com características culturais distintas, nesse caso, o desenvolvimento gerencial local atento ao global.

Outro conceito a ser incorporado nos currículos seria o da aprendizagem na ação (RAELIN, 2006; 2011), com a utilização de experiências que vão além da sala de aula. Antonello e Ruas (2005) destacam bem a importância desse tipo de aprendizagem para o desenvolvimento gerencial. Aqui, as práticas da aprendizagem informal e incidental aconteceriam, principalmente, através de interconexões e teias de participação que os alunos no mundo social e organizacional vivem. As experiências de aprendizagem, como práticas compartilhadas, são muitas vezes sustentadas através de comunidades de prática e/ ou rede informal de aprendizagem (WENGER, 1996; BROOKFIELD, 1986; LAVE e WENGER, 1991; BROWN e DUGUID, 1991; 2001; BOUND e MIDDLETON, 2003).

Com relação às ferramentas e tecnologias utilizadas nos programas, observa-se o uso de estudos de caso, jogos de empresa, seminários e ambientes virtuais de aprendizagem como o Moodle. Cabe lembrar que a experimentação ativa em programas desse tipo deveriam articular o currículo, as tecnologias educacionais e a prática dos discentes. Assim, os processos de aprender e ensinar, desejáveis na contemporaneidade, ocorre na configuração de espaços de relação e interação entre todos esses elementos.

Dessa forma, é importante revisitar novas estratégias de ensino-aprendizagem, incluindo a utilização da tecnologia digital virtual (TDV). O trecho a seguir explicita isto:

[...] a gente vive cada vez mais num mundo virtual, então o MBA vai ter que encarar essa realidade, presencialidade, essa limitação temporal e espacial que a sala de aula hoje apresenta. Ela vai ter que ser diminuída, nunca vai deixar de existir a sala de aula, alguns momentos da sala de aula são muito importantes, mas alguns momentos que hoje em sala de aula não são importantes, então a gente vai ter que trabalhar o virtual junto como esse processo, até porque o virtual causa uma mudança de comportamento no aluno que é muito positiva, o aluno sai de uma posição passiva em sala de aula, uma posição ativa (Entrevista C3, 2011).

Por fim, analisando o público-alvo que busca este tipo de formação, observa-se que a formação acadêmica de base é a mais variada possível, muitas vezes dificultando o avanço e aprofundamento das discussões sobre o estado da arte das práticas e modelos de gestão. Em torno de 50\% dos alunos são egressos da própria IES, e a inserção no mundo do trabalho acontece via graduação e pós-graduação, para aumento da sua empregabilidade. Os dados encontrados são coerentes com as pesquisas (BARUCH e PEIPERL, 2000; FREZATTI e KASSAI, 2003) realizadas sobre o papel que os cursos de pós-graduação assumiram no cenário nacional. Além disso, também corroboram a pesquisa da ANAMBA (2011).

Contribuindo com essa discussão, os profissionais que atuam com formação gerencial, como consultores ou docentes de programas de pós-graduação lato sensu, ao serem questionados sobre suas percepções com relação à oferta desse tipo de programa (figura 3), apontam a mescla teoria e prática que um programa de 
pós-graduação deveria proporcionar, concordando o exposto na figura 3 sobre os objetivos de um programa de pós-graduação lato sensu, no que tange à capacitação e formação gerencial.

Figura 3

\section{Mapa 3 - Percepção dos especialistas}

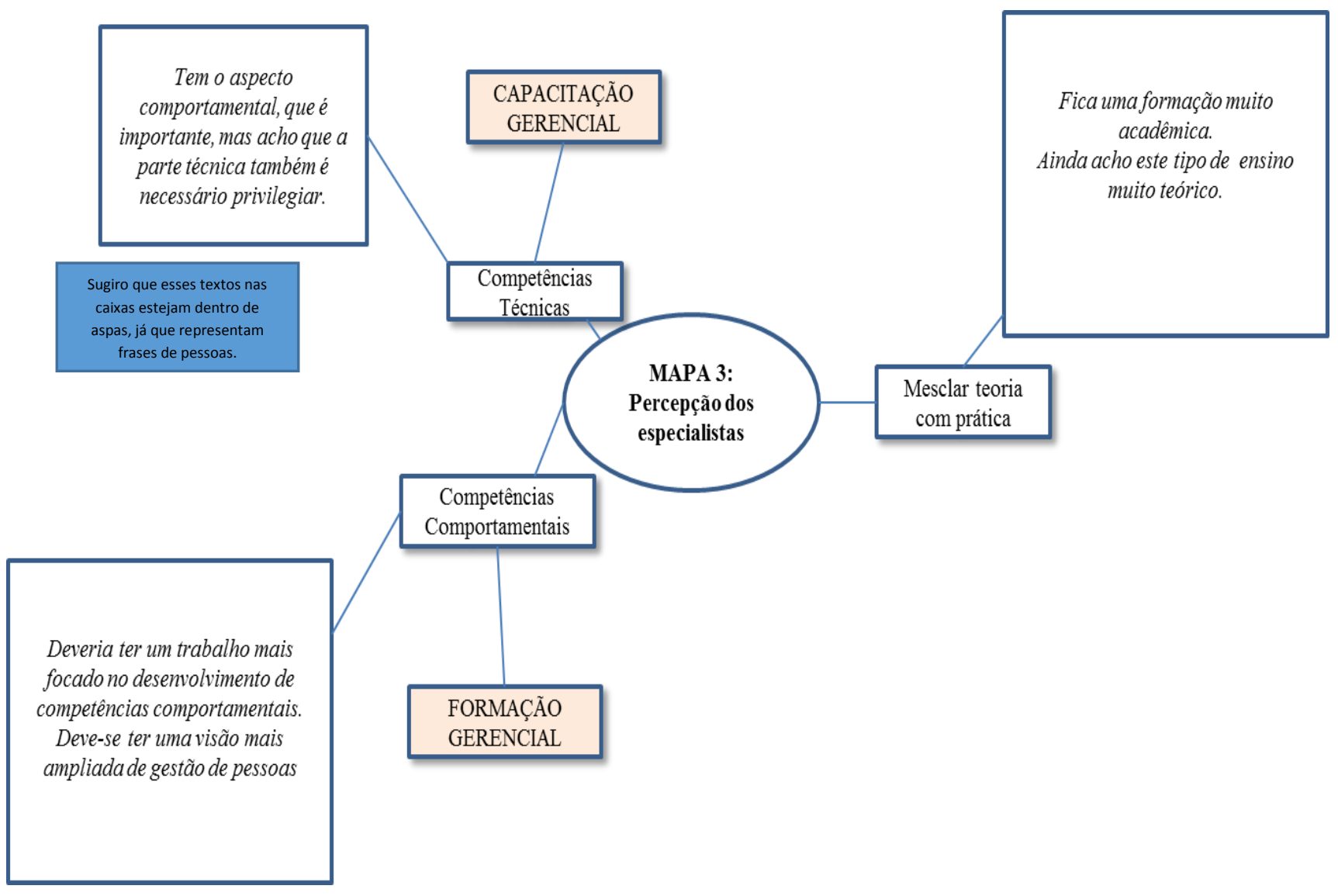

Fonte: Dados da pesquisa.

Ao reforçarem a mistura entre teoria e prática, esses especialistas acreditam que:

[...] a empresa identifica uma necessidade ou, em alguns casos, muitos poucos casos, a universidade participa de um diagnóstico e depois faz uma proposta, mas posso te dizer que 95\% dos casos a empresa vem com uma demanda, teoricamente já teria um diagnóstico que tem uma demanda específica e a universidade customiza um produto, ou seja, um projeto de desenvolvimento de competências em função dessa demanda. (entrevista E5, 2011). [...] como preparar esse gestor pra lidar com essa série de situações que estão acontecendo, por exemplo, a rotatividade das pessoas, a geração y, as pessoas, essas geração y querendo crescer dentro das organizações com muita rapidez e os gestores não conseguindo acompanhar isso, a empresa não conseguindo oferecer nessa mesma proporção (Entrevista E4, 2011). [...] percebo um grande esforço de busca, de aperfeiçoamento, de atualização, de buscar novos assuntos (Entrevista E6, 2011). 
Nesse sentido, a reflexão sobre o que é inovar em educação deve estar imbricada a esses elementos. Rios (2002) considera que o termo "inovação" vem atrelado à novidade, porém, ela traz benefícios? É renovadora? Implica em melhoria? Inovação na educação deveria ser entendida como ruptura paradigmática (PALMA e FOSTER, 2011), que aconteceria tanto no projeto politico pedagógico, expresso em um currículo contemporâneo, como na contribuição da TDV, observada no incremento de soluções tecnológicas, suscitando um novo conceito de aprendizagem, a extrema, que potencializa e acrescenta novas abordagens em sala de aula. Tais soluções seriam o uso de podcasting, blogs em tempo real, webcasts, focus group, mlearning, second life entre outros, ampliando a conexão entre teoria e prática na formação gerencial.

\section{Conclusões e Recomendações}

Avanços nas pesquisas sobre as organizações permitem uma ampla discussão sobre a efetividade dos programas de pós-graduação relacionados com a formação gerencial. Observa-se, cada vez mais, uma crescente preocupação com os investimentos realizados e a incorporação na vida organizacional, de conceitos, práticas e princípios que ajudem as empresas e seus gestores a resolverem problemas e tomarem decisões mais assertivas e com perspectiva sistêmica. A perspectiva de que a certificação que um programa de pós-graduação lato sensu geraria maior empregabilidade à força de trabalho gerencial deve também ser analisada através de indicadores globais da economia do país.

O avanço do neoliberalismo no Brasil, na esfera educacional, proporcionou a entrada de novos atores no ensino superior, principalmente nos cursos de pós-graduação lato sensu, deixando de ser um serviço de bem comum para se tornar um produto a ser comercializado (GUIMARAÇÕES-IOSIF e SANTOS, 2012). Esse avanço foi observado pelo aumento de oferta de produtos e serviços, nas instituições de ensino superior de âmbito privado, gerando pacotes instantâneos de MBA's brasileiros ou não (ALMEIDA FILHO, 2008). Esse movimento criou, segundo Oliveira (2009) um próspero e grande mercado, cujo caráter primordial é a perspectiva de ganho financeiro por parte das instituições promotoras desse tipo de ensino. Isso pode ser observado pelo fato de que os 3 maiores grupos educacionais atuais do Brasil pertencem à Anhanguera, Kroton e Estácio, com 24,2\% da fatia do mercado de ensino superior (SILVA, 2012).

O discurso atual sobre trabalho, qualificação e competências aponta o conhecimento e a inovação como fatores de competitividade, que, se por um lado, o mundo organizacional reconhece que a aprendizagem é um dos fatores de produção, sendo o homem/mulher um bem de capital (LUDWIG, 1998), por outro, ainda preconiza que o capital tangível é o que merece investimentos. Eis aqui um nó a ser desfeito, pois pensar sobre as noções de qualificação e competência na formação gerencial é investir na formação e capacitação dos próprios gestores, oferecendo maior autonomia e poder decisório, delegando e descentralizando as informações e conhecimentos, no dia a dia organizacional. Pensar em formação gerencial é também considerar que o individuo está ligado ao seu contexto e o processo de construção da sua identidade, com o desejo de tornar-se indivíduo, de criar uma história pessoal, de atribuir significado a todo conjunto de experiência da vida individual. Impõe-se, assim, verificar as reais possibilidades de ampliação dessa formação gerencial com as possibilidades reais de autonomia e superação do trabalho prescrito e enriquecimentos das atividades, para além dos portões das fábricas e escritórios.

Wood Jr. e Cruz (2014) destacam que a narrativa da progressão na carreira, sob a ótica da esfera individual, proposta por um discurso instrumental desse tipo de produto acadêmico (MBA) ainda pode ser vista, porém travestida com uma roupagem socialmente responsável.

A articulação de situações de aprendizagem, vivenciadas em uma pós-graduação, com as situações de trabalho, deveria favorecer a integração entre esses dois mundos, o acadêmico e o das organizações. Dessa forma, a concepção desse tipo de formação gerencial deveriam integrar, simultaneamente, investigação e ação, conforme proposto por Antonello e Ruas (2005), favorecendo a inclusão de novas perspectivas e abordagens nos currículos e na própria forma de conduzir o ensino e a aprendizagem gerencial. 
Esse estudo também revelou que a formação gerencial ainda tem um ensino hierarquizado pela estrutura das disciplinas no currículo, com metodologias de ensino e avaliação tímidas, com relação ao uso pleno da metodologia do caso e das TDVs e, muitas vezes, sem a incorporação de uma perspectiva dos estudos organizacionais críticos (CHOO, 2007) na educação gerencial, privilegiando currículos mais ortodoxos do que críticos.

Dessa forma, pode-se vislumbrar o longo caminho que as próprias IES têm pela frente, gerando grandes desafios para alinhar os programas de pós-graduação lato sensu, ou seja, promovendo a articulação, de forma complexa e sistêmica, desde a concepção do programa, que procuraria integrar formação e ação, gerando uma práxis formativa, até a incorporação de características de uma educação e formação gerencial crítica, envolvendo reflexões sobre o conteúdo dos programas (objetivo e currículo), o processo (ensinar e aprender) e contexto regional no qual é oferecido este programa.

Os resultados encontrados nesse estudo, ao contrário de ser considerado como algo acabado e finito, podem seguir novos caminhos e rumos, oportunizando novas indagações e reflexões sobre os temas em estudo. Mesmo tendo como aspecto limitador a quantidade de IES pesquisadas, há indícios de que, mesmo no âmbito nacional, a situação da oferta deste tipo de produto e sua real contribuição para a formação de um gestor, não avançam na construção de um sujeito critico e emancipado.

Recomenda-se que possam ser realizados aprofundamentos que possam ser realizados:

- De uma coleta de dados ampliada com as IES faltantes, incluindo a de cunho público para complementação dos dados, bem como a inclusão de um maior número de especialistas, para a validação dos resultados aqui encontrados;

- Da abertura de um debate sobre os programas de pós-graduação lato sensu MBA. Qual o seu objetivo? Como estruturar um projeto pedagógico inovador, mais crítico e contemporâneo? Como atender as demandas locais e globais? Como incorporar novas formas de aprendizagem e avaliação?;

- A busca de uma maior compreensão, com relação aos aspectos da aprendizagem informal e a TDV no âmbito das IES e das próprias organizações e sua contribuição para o estudo da formação gerencial;

- Da inclusão de uma perspectiva crítica sobre a formação gerencial;

- Essas questões mereceriam novos estudos com o objetivo de realizar avanços nessa área de conhecimento e promover um aprofundamento para a realidade brasileira no que se refere a uma abordagem de aprendizagem nas organizações.

Por fim, o tema é instigante e nos oferece algumas reflexões, entre elas: como "vencer" as estruturas burocráticas e hierarquizadas das IES na busca de um novo formato de pós-graduação lato sensu? A incorporação de pesquisa de mercado e diagnósticos sobre necessidades de formação gerencial agregaria valor a estes programas? Se sim, como inseri-las no contexto legal e pedagógico desse processo? Como efetivamente compreender a sustentabilidade e o efeito desse tipo de programa na ação gerencial? Ficam estas e, provavelmente, outras questões levantadas pelo próprio leitor para a ampliação do debate desse tema. 


\section{Referências}

ALMEIDA Filho, N. Universidade Nova no Brasil. In: SANTOS, B. S; ALMEIDA FILHO, N. A universidade no século XXI: para uma universidade nova. Coimbra: Almedina, 2008.

ANAMBA. Associação Nacional de MBAs. Disponível em: <www.anamba.com.br〉. Acesso em março de 2014.

ANTONACOPOULOU, E. P. The relationship between individual and organizational learning: new evidence from managerial learning practices. Management learning, v. 37, n. 4, p. 455-473, 2007.

ANTONELLO, C.; RUAS, R. Formação gerencial: pós-graduação Lato sensu e o papel das comunidades de práticas. Revista de Administração Contemporânea, v. 2, n. 9, p. 1-17, abril/jun. 2005.

ASCHER, K. Master of business? Human Resource Management Journal, v. 2, n. 10, p. 78-98, 2000.

BAUER, M.; AARTS, B. A construção do corpus: um princípio para a coleta de dados qualitativos. In: BAUER, M.; ASKELL, G. (Orgs.). A pesquisa qualitativa com texto, imagem e som. Petrópolis: Vozes, 2002.

BOLT, J. Achieving the CEO's agenda: education for executives. Academy Management Review, n. 5, p. 44-48, 1993.

BOUND, D.; MIDDLETON, H. Learning from others at work: communities of practice and informal learning. Journal of workplace learning, v. 5, n. 15, p. 194-202, 2003.

BREWER, P.; BREWER, K. Knowledge Management, Human Resource Management, and Higher Education: A Theoretical Model. Journal of Education for Business, v. 85, n. 6, p. 330-335, 2010.

BROOKSFIELD, S. Understanding and facilitating adult learning. Califórnia: Jossey-Bass, 1986.

BROWN, J.; DUGUID, P. Organizational learning and communities of practice: toward a unified view of working, learning and innovation. Organization Science, v. 1, n. 2, p. 40-57, 1991.

BUARQUE, C. A aventura da universidade. Rio de Janeiro: Paz e Terra, 1994.

BURGOYNE, J.; STUART, R. Teaching and learning methods in management development. Personnel Review, v. 3, n. 20, p. 27-33, 1991.

CARUSO, L.; PERO, V. Trajetórias intersetoriais, empregabilidade e reconversão profissional dos trabalhadores desligados da indústria. Anais da Reunião Nacional da Anpocs, Caxambú, SP, Brasil, 1996.

CHOO, K. Can critical management education be critical in a formal higher educational setting? Teaching in Higher Education, v. 4, n. 12, p. 485-497, 2007.

CLOSS, L.; ANTONELLO, C. Aprendizagem transformadora: a reflexão crítica na formação gerencial. Cad. EBAPE.BR, v. 8, n. 1, p. 19-37, 2010.

COLLINS, D. Performance level evaluation methods used in management development studies from 1986-2000. Human Resource Development Review, n. 1, p. 91-110, 2002.

DAVEL E.; MELLO, M. Gerência em ação: singularidades e dilemas do trabalho gerencial. Rio de Janeiro: FGV, 2005.

DELEUZE, G.; GUATARRI, F. Mil platôs: capitalismo e esquizofrenia. Rio de Janeiro: Editora 34, 1995.

DEMO, P. Os desafios modernos da educação. Petrópolis: Vozes, 1996.

DEMO, P. Participação é conquista: noções de política social participativa. São Paulo: Cortez, 1999. 
DIONNE, P. The evolution of training activities. Human Resource Development Quartely, v. 3, n. 7, p. 279-286, 1996.

DOYLE, M. Organizational transformational and renewal: a case for reframing management development? Personnel Review, v. 6, n. 24, p. 6-18, 1994.

EBOLI, M. Educação Corporativa no Brasil: mitos e verdades. São Paulo: Gente, 2004.

FERRETI, C. Novas tecnologias, trabalho e educação: um debate multidisciplinar. Petrópolis: Vozes, 1994.

FLICK, U. Uma introdução à pesquisa qualitativa. Porto Alegre: Bookman, 2004.

FORQUIN, J. As abordagens sociológicas do currículo: orientações teóricas e perspectivas de pesquisa. Educação e Realidade, v. 1, n. 21, p. 187-198, 1996.

FREZATTI, F.; KASSAI, S. Estudo do impacto de um curso MBA em controladoria na evolução dos seus egressos. Revista Contabilidade e Finanças, v. 14, n. especial, p. 54-65, 2003.

FRIEDMAN, T. O mundo é plano: uma breve história do século XXI. São Paulo: Objetiva, 2009.

FRIGOTTO, G. Educação e crise do trabalho: perspectivas de final de século. Petrópolis, RJ: Vozes, 1998.

GIL, A. Métodos e técnicas de pesquisa social. São Paulo: Atlas, 1989.

GITAHY, L.; RABELLO, F. Educação e Desenvolvimento tecnológico: o caso da indústria de autopeças. Educação \& Sociedade, v. 45, n. 14, p. 225-251, 1993.

GUIMARÃES-IOSIF, R. M.; SANTOS, A. V. A governança contemporânea na educação superior brasileira: atores, disputas e desafios. In: GUIMARÃES-IOSIF, R. M.; SANTOS, A. V. (Orgs.). Politica e governança educacional: disputas, contradições e desafios diante da cidadania. Brasília: Universia, Liber Livro, 2012.

HAY, A.; HODGKINSON, M. More success than meets the eye: a challenge to critiques of the MBA: possibilites for critical management education? Management learning, v. 39, n. 1, p. 21-40, 2008.

HILL, L. Desenvolvendo as estrelas do desempenho. In: HESSELBEIN, F.; COHEN, P. (Orgs.). De líder para líder. São Paulo: Futura, 1999.

KARAWEJCZYK, T. A articulação entre mudança e aprendizagem organizacional. Doutorado (Tese em Administração). Universidade Federal do Rio Grande do Sul, Porto Alegre, 2005.

LAVE, J.; WENGER, E. Situated learning: legitimate peripheral participation. Cambridge: Cambridge University Press, 1991.

LE BOTERF, G. Desenvolvendo as competências dos profissionais. 3. ed. Porto Alegre: Artmed, 2003.

LE GOFF, J. A história nova. São Paulo: Martins Fontes, 2001.

LEVY-LEBOYER, C. Lê bilian de compétence. Paris: Les Editions d' Organisation, 1996.

LOBO FILHO, R. Novos rumos do ensino privado. Folha de São Paulo, São Paulo, seção tendências e debates, 23. jul.1996.

LORANGE, P. Back to school: executive education in the us. Chief Executive, v. 92, n. 6, p. 36-39, 1994.

LOVE, C. Developing management education in the countries of the former soviet bloc: critical issues for ensuring academic quality. Innovations in Education and Teaching International, v. 4, n. 43, p. 421-434, 2006.

LUDWIG, W. Você S/A sua marca, sua palma. Revista treinamento \& desenvolvimento, v. 2, n. 24, p. 18-19, 1998. 
MACIEL, H.; SILVA, A. As relações de trabalho e a ação gerencial: um estudo em bancos privados. Revista de Negócios, v. 1, n. 17, p. 21-40, 2012.

MALHOTRA, N. Pesquisa de Marketing: uma orientação prática. 3. ed. Porto Alegre: Bookman, 2001.

MANFREDI, S. M. Trabalho, qualificação e competência profissional - dimensões conceituais e políticas. Educação \& Sociedade, v. 64, n. 29, p. 13-49, 1998.

MARSHALL, C.; ROSSMAN, G. Designing qualitative research. Thousand Oaks: Sage, 1999.

MATURANA, H. Transformación en la convivencia. Santiago de Chile: Dólmen Ediciones, 1999.

MATURANA, H.; REZEPKA, S. Formação e capacitação humana. Petrópolis: Vozes, 2008.

MATURANA, H.; VARELA, F. A árvore do conhecimento: as bases biológicas da compreensão humana. São Paulo: Palas Athena, 2002.

MELlo, G. Cidadania e Competitividade: desafios do terceiro milênio. São Paulo: Cortez, 1993.

MINTZBERG, H. The manager's job: folklore and fact. Harvard Business Review, v. 8, n. 16, p. 49-61, 1990.

MINTZBERG, H.; GOSLING, J. Reality programming for MBAs. Strategy and Business, v. 9, n. 1, p. 21-23, 2002.

MINTZBERG, H.; LAMPEL, J. Do MBAs make better CEOs? Sorry, Dubya it ain’t necessarily so. Fortune, v. 142 , n. 19, p. 244-248, 2001.

MORIN, E. Ciência com consciência. Rio de Janeiro: Bertrand Brasil, 1996.

MORIN, E. Os sete saberes necessários à educação do futuro. São Paulo: Cortez; Brasília, DF: UNESCO, 2001.

MOSS, G. et al. The Interactive Whiteboards, Pedagogy and Pupil Performance Evaluation: An Evaluation of the Schools Whiteboard Expansion (SWE) Project: London Challenge DfES Research Report 816, London: DFES, 2007.

MOTTA, P. Gestão Contemporânea: a Ciência e a Arte de ser Dirigente. 10. ed. Rio de Janeiro: Record, 2000.

MOURA, M.; BITENCOURT, C. A articulação entre estratégia e o desenvolvimento de competências gerenciais. RAE-Eletrônica, v. 1, n. 5, artigo 3, 2006.

NEVES, C. Ensino superior privado no Rio Grande do Sul: a experiência das universidades comunitárias. São Paulo: Nupes/USP, documento 06, 1993.

NICOLINI, A. Qual será o futuro das fábricas de administradores? Revista de Administração de Empresas, v. 2 , n. 43, p. 44-54, 2003.

OLIVEIRA, F. Inovando na pós-graduação: a experiência do MBA da EAESP/FGV. Revista de Administração de Empresas, v. 36, n. 1, p. 6-12, 1996.

PAIVA, V. O novo paradigma de desenvolvimento: educação, cidadania e trabalho. Educação \& Sociedade, v. 45, n. 14, p. 309-326, 1993.

PAIVA, V. Anos 90: as novas tarefas da educação dos adultos na América Latina. Cadernos de Pesquisa, v. 89, n. 1, p. 29-38, 1994.

PALMA, G.; FORSTER, M. Inovação e educação superior: rupturas e continuidades. Educação Unisinos, v. 15, n. 2 , p. 149-157, 2011.

PERIN, M. et al. O impacto da formação gerencial no desempenho organizacional à luz da abordagem de competências. Brazilian Business Review, v. 6, n. 1, p. 104-120, 2009. 
POCHMANN, M. Juventude em busca de novos caminhos. In: VANNUCHI, P. (Org.) Juventude e sociedade: trabalho, educação, cultura e participação. São Paulo: Fundação Perseu Abramo, 2004.

RAELIN, J. Developing managers as learners and researchers: using action learning and action research. Journal of Management Education, v. 30, n. 5, p. 670-689, 2006.

RAELIN, J. Updating the state-of-the-practice of emotions in management education: the integrated emotions exercise. International Journal of Management Education, v. 9, n. 4, p. 13-24, 2011.

RAMOS, M. Possibilidades e desafios na organização do currículo integrado. In: FRIGOTTO, G.; FRANCO, M.; RAMOS, M. (Orgs.). Ensino médio integrado: concepção e contradições. São Paulo: Cortez; Rio de Janeiro: Escola Politécnica de Saúde Joaquim Venâncio, 2005.

RIOS, T. Competência ou competências: o novo e o original na formação de professores. In: ROSA, D.; SOUSA, V. C. de; FELDMAN, D. (Orgs.). Didáticas e práticas de ensino: interfaces com diferentes saberes e lugares formativos. Rio de Janeiro: DPA\&A, 2002.

RUAS, R. Mestrado Modalidade Profissional: em busca da identidade. Revista de Administração de Empresas, v. 43, n. 2, p. 55-63, 2003.

RUAS, R. COMIDI, G. M. Aprendizagem e desenvolvimento de competências: articulando teoria e prática em programas de pós-graduação em formação gerencial. Cad. EBAPE.BR., v. 5, n. edição especial, p. 1-14, 2007.

SANTOS, B. de S. Pela mão de Alice: o social e o político na pós-modernidade. 2.ed. São Paulo: Cortez, 2010.

SANTOS, R. et al. Uma reflexão metodológica sobre a pós-graduação lato sensu no Brasil. Revista ANGRAD, v. 8, n. 4, p. 489-499, 2007.

SCHLEMMER, E. Ava: um ambiente de convivência interacionista sistêmico para comunidades virtuais na cultura da aprendizagem. Tese (Doutorado em informática na educação). Universidade Federal do Rio Grande do Sul, Porto Alegre, 2002.

SILVA, S. Um jogo para profissionais. Revista Ensino Superior, São Paulo, v. 14, n. 163, p. 28-33, 2012.

SIMÕES, C. Educação técnica e escolarização de jovens trabalhadores. In: MOLL, J. (Org.). Educação profissional e tecnológica no Brasil contemporâneo: desafios, tensões e possibilidades. Porto Alegre: Artmed, 2010.

SOUZA, P. R. Educação, economia e sociedade: um mundo novo e uma nova educação. In: FISCHER, A.; MORAES, F.; AMORIN, W. (Orgs.). Educação corporativa: fundamentos, evolução e implantação de projetos. São Paulo: Atlas, 2010.

THOMPSON, J. Ideologia e cultura moderna: teoria social critica na era dos meios de comunicação de massa. Petrópolis: Vozes, 1995.

VERGARA, S. Projetos e relatórios de pesquisa em administração. 9. ed. São Paulo: Atlas, 2007.

VIERIA, A.; LUZ, T. Do saber aos saberes: confrontando as noções de qualificação e competência. Anais do Encontro da Associação Nacional de Pós-Graduação e Pesquisa em Administração. São Paulo, SP, Brasil, 2003.

WENGER, E. Communities of practice: the social fabric of a learning organization. The Healthcare forum journal, v. 39, n. 4, p. 20-27, 1996.

WOOD Jr., T. Cuidado: MBAs pensando. Carta Capital, 12 de dezembro de 2001.

WOOD Jr., T.; CRUZ, J. F. P. MBAs: cinco discursos em busca de uma nova narrativa. Cad. EBAPE.BR., v. 12, n. 1, p. 26-44, 2014.

ZARIFIAN, P. Objetivo competência: por uma nova lógica. São Paulo: Atlas, 2001. 